ARTIGOS 



\section{CABEÇAS CORTADAS DA MESOAMÉRICA}

Sérgio Medeiros*

Ao falar de corpos e cabeças no Popol Vuh, poema maia do século XVI, escrito na Guatemala na língua maia-quiché com o recurso dos caracteres latinos, tomarei como referência a edição brasileira dessa obra, publicada em 2007. Nessa edição, preparada pelo professor Gordon Brotherston e por mim, o poema maia está dividido em quatro cantos. A edição brasileira segue a tradução do texto para o inglês, publicada por Munro Edmonson em 1971. Quando iniciamos a tradução do poema, Edmonson nos autorizou a usar sua edição bilíngüe quichéinglês como fonte e modelo. No prefácio que escrevemos para a edição brasileira, afirmamos: "Para os aspirantes a tradutores que decidam seguir seus passos, a versão de Edmonson possui várias vantagens evidentes: ela inclui uma transcrição do original quiché; leva em conta a estruturação em versos do original quiché; e compara meticulosamente as soluções que tradutores anteriores deram a passagens opacas e difíceis". ${ }^{1}$

Gostaria de comentar, inicialmente, a estruturação em versos do texto e, a seguir, o uso da voz passiva, que a edição brasileira adotou. Faz-se necessário citar um exemplo. Tomo-o do "Primeiro Canto"2:

Quatro criações,

Quatro humilhações, como contavam,

Feitas por Tzakol,

Bitol,

A Mãe

E o Pai

Da vida

E da Humanidade,

O Inspirador

E Animador,

Gerador

* Sérgio Medeiros traduziu o Popol Vuh (lluminuras, São Paulo, 2007), com o auxílio de Gordon Brotherston, trabalho indicado ao prêmio Jabuti de melhor tradução. Leciona literatura na UFSC e publicou três livros de poesia. Co-edita o site de arte e cultura: www.centopeia.net 
12 REVISTA ESBOÇOS N ${ }^{\circ} 20$ - UFSC

E animador da

Luz

E da Corrida,

Zaqil al (Filhos da Mãe da Luz)

Zaqil qahol (Filhos do Pai da Liz),

O Meditador,

O Pensador

De Tudo

$\mathrm{O}$ que existe:

Céu,

Terra,

Lago

E Mar

U kah tzuquxik,

U kah xukutaxik,

$R$ etaxik,

U kah cheexik,

Umeh q'aamaxik,

Uyuq q'aamaxik.

Upam kah,

Upam ulev.

Kah tzuq

Kah xukut, ch uch'axik

$R$ umal ri Tzakol

Bitol,

Uchuch,

U qahav

$K$ 'azilem,

Vinaqirem,

Abanel,

K'uxilanel,

Alay e ech,

K'uxilay r ech 
Zaqil,

Amaq'il,

Zaqil al,

Zaqil q'ahol,

Ah biz,

Ah naoh

Chi r ech r onohel,

A to q'ool vi:

Kah,

Ulev,

Cho,

Palov.

Gostaria de chamar a atenção, inicialmente, para o fato de que, não apenas nesse trecho, mas em todo o poema, o elemento feminino (mãe) precede o masculino (pai): o primeiro é citado num verso e, o segundo, em outro verso. Ao lado dessa regra, deve-se mencionar o uso da voz passiva, ou seja, indicase no poema ameríndio, por meio dessa voz, que o sujeito recebe a ação verbal. O paradigma da cosmogonia maia seria, então, uma frase como: "O mundo foi feito por mim", ou "Os animais são feitos por mim", ou "O homem será feito por mim".

Abrindo um pequeno parêntese, considero o Popol Vuh uma cosmogonia porque narra a origem do mundo e também a criação dos seres humanos, que foram modelados, destruídos e remodelados ao longo do tempo, adquirindo, depois de algumas tentativas frustradas, sua forma atual e definitiva. Uma cosmogonia poderá ser múltipla, feita de grandes e pequenas criações, de gestos enormes e gestos mínimos. A criação bíblica não é o único modelo de cosmogonia de que dispomos. Nesse sentido, seguindo a lição de Michel Serres, autor de um ensaio sobre a gênese ocidental, eu poderia afirmar que o Popol Vuh é um livro que fala de vários começos e que, por isso, é o livro dos começos, ou dos devires numerosos. As coisas do mundo começam, se destroem e depois recomeçam. As coisas também se interrompem, se separam, depois se reconectam, fazendo o mundo avançar. O tempo é múltiplo e os corpos são muito frágeis ou perfeitos demais, é preciso, então, encontrar o meio-termo, daí, segundo entendo, a razão de tantas criações e destruições nesse poema maia.

Fechado agora o parêntese e voltando à questão da tessitura lingüística do texto, em sua versão para o inglês e para o português, acredito que tais 
esclarecimentos, apresentados anteriormente, servirão para mostrar que, a partir de Edmonson, é possível afirmar que a literatura maia-quiché, ou, mais especificamente, o Popol Vuh, é um tipo de texto que faz uso do dístico (grupo de dois versos, ou parelha) e da voz passiva e da passividade. A discussão do corpo humano e da cabeça cortada, que esboçarei a seguir, porá em cena sempre, através dos exemplos que citarei, essa estrutura poética e essa voz verbal, e também mostrará o elemento feminino precedendo o masculino.

Mencionei acima as quatro criações. "Identificar e computar essas criações não tem sido fácil”, como reconhece Gordon Brotherston. "Ao discernir nelas as etapas de formas específicas de vida, dentro de uma narrativa evolutiva, Edmonson fala de seus inícios e finais como 'nascimentos e humilhações'. Tedlock, por outro lado, adere à costumeira preferência espacial e apresenta as quatro criações como 'formadas e repartidas em quatro partes, assinaladas e medidas... nos quatro ângulos, nos quatro lugares'. Dado o vasto escopo da narrativa, parece provável que os termos-chave maias em questão $(t z u q, x u k u t)$ incluam as duas possibilidades, neste caso a configuração americana do espaço e o percurso evolutivo do próprio texto descartariam um modelo espacial do qual estivesse ausente o tempo". ${ }^{3}$ Considerando especificamente o conteúdo cosmogônico e deixando de lado a história quiché, narrada na última parte do Popol Vuh, podemos agora elencar as seguintes 'idades' ou 'fases' do período cosmogônico, correspondendo, a cada idade ou fase, um tipo de criação e de destruição: 1. Gente de barro; 2. Gente de madeira; 3. Os proto-humanos, destacando-se Vuqub Kaqix (Sete papagaio) e família; e 4. Gente do Inframundo ou Xibalba, seguido de um período de transição para a história, período em que são criados, finalmente, os homens de milho, os homens atuais, criação que relaciona o Inframundo à superfície da Terra, mostrando ou revelando que são interdependentes. Em outras palavras, o Inframundo é também fonte da vida e não apenas o reino da morte. Após serem criados, os homens de milho se recordarão das quatro criações e das quatro humilhações, ou seja, segundo o Popol $V u h$, as quatro criações ocorreram num período anterior à modelação do seu corpo pelos deuses.

Recentemente, num colóquio na USP sobre arte mesoamericana e andina, tive a oportunidade de discutir o Popol Vuh com especialistas no tema e alunos de graduação e pós-graduação. Lembro que enfatizei o fato de o texto maia incluir mito e história, biologia e matemática, filosofia e geometria, poesia e prosaísmo, não se enquadrando num gênero narrativo único. Trata-se de um texto poderosamente multifacetado, espécie de enciclopédia do saber indígena.

Não pretendo resumir o enredo de um livro tão complexo, mas destacar um pequeno fragmento do Terceiro Canto, que fala de um sacrifício e de uma cabeça separada do corpo, tema deste breve ensaio ${ }^{4}$ : 
E então eles foram sacrificados

E foram enterrados

No Pátio Empoeirado, como é chamado,

Eles foram enterrados então.

A cabeça de Hun Hun Ah Pu foi cortada.

Só seu corpo foi enterrado com seu irmão mais jovem.

"Ponha essa cabeça dele na árvore

Que cresce na estrada",

Disseram então Hun Kame

E Vuqub Kame.

E assim então sua cabeça foi levada e deixada na árvore,

E então a árvore frutificou.

Ela nunca havia dado frutos,

Antes de receber a cabeça de Hun Hun $\mathrm{Ah} \mathrm{Pu}$.

E assim o que chamamos cabaceira hoje

É a cabeça de Hun HUn Ah Pu, conta-se.

E assim Hun Kame

E Vuqub Kame se admiraram

Do fruto da árvore.

O fruto redondo estava em toda parte,

E não dava para saber

Onde a cabeça de Hun Hun Ah Pu ficara,

Era exatamente

Igual a uma cabaça.

Ta x e puz q'ut,

X e muq q'ut.

Chi Puqubal Chaah u bi

X е тиq vi.

$X$ qát u holom ri Hun Hun Ah Pu.

$X a$, u nimal $x$ muqik $r$ uq ri, u ch'ak'.

"Chi ya ri, u holom, xol chee 
Ri tikil pa be,"

$X$ ch'a q'ut Hun Kame,

Vuqub Kame.

Ta $x$ be q'u ya 'ok u holom xol chee,

Ta $x$ vachin q'u ri chee.

Ma ha bi, u vach.

Ma ha ch ok o ri, u holom ri Hun Hun Ah Pu ch uxol chee.

Are q'u ri tzima $k$ oh ch'a chi re vakamik

U holom Hun Hun Ah Puc h uch'axik.

Ta $x$ u mayihah q'ut Hun Kame,

Vuqub Kame

U vach ri chee.

Hum ah k'olok'aq u vach

Ma q'u q'alah

Q'o chi vi ri, u holom Hun Hun Ah Pu.

Xa hunam chik $u$ vach

$R$ uq u vach tzima.

Essa cena se passa no Inframundo, ou Xibalba. A vida e a morte não estão separadas no poema maia. O herói Hun Hun $\mathrm{Ah} \mathrm{Pu}$ (Um Caçador), futuro pai dos famosos Gêmeos, após ser morto pelos Senhores de Xibalba, torna-se uma "cabeça falante", oculta entre vários frutos redondos. Um belo dia, uma índia virgem, X Kiq (Moça de Sangue), desobedecendo a uma ordem paterna, aproximase sorrateiramente da cabaceira, declarada já árvore-tabu e sob a qual ninguém deveria passar. Eis a cena, uma das mais famosas do Popol Vuh $h^{5}$ :

Assim ela foi sozinha

E chegou lá

Sob a árvore,

Plantada no Pátio Empoeirado.

“Ah! O que é o fruto desta árvore?

Não é delicioso o que esta árvore dá?

Eles não devem se estragar;

Não devem ser desperdiçados. 
E se eu pudesse cortar um só?",

Disse a mocinha então.

E então falou a caveira

Que estava lá na árvore:

"Por que você deseja estas meras caveiras

Que se tornaram redondas nos galhos das árvores?",

Foi o que a caveira de Hun $\mathrm{Ah} \mathrm{Pu}$ disse

Quando ele falou à mocinha.

"Você não as quer",

Foi-lhe dito.

"Eu as quero muito",

Disse a mocinha então.

"Está bem, você deve erguer sua mão direita.

Você vê agora?", disse a caveira.

"Sim",

Disse a mocinha então.

E estendeu

A mão direita diante da caveira.

E assim a caveira lançou sobre ela sua saliva,

Que caiu então na palma da mão da mocinha.

Assim então ela olhou para o que estava na sua mão;

Ela examinou imediatamente aquilo.

Mas o cuspo da caveira não estava na sua mão"

Kate $x$ beek $x a$, u tukel

$X$ apon q'ut

Ch u xe chee tikil

Chi Puqubal Chaah tikil vi.

"Hiyaa! Naki pe, u vach wae chee?

Ma ki pa quz chi vachin va chee?

Ma ki kam tah:

Ma ki zach tah.

La kit a $x$ ch in ch'up hun ok? "

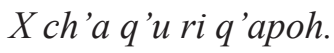


Ta x ch'av q'ut ri baq

$Q$ 'o 'ula xol chee,

"Naki pa ka rayih chi r e rixa baq

Ri k'olok'oxinak chu u q'ab tak chee?"

$X$ ch'a ri, u holom Hun Ah Pu

Ta x ch'avik chi re ri q'apoh.

"Ma ka rayih,"

X uch'axik.

"Ka nu rayih,"

Xch'a q'ut ri q'apoh.

“Utz ba la, ch a lik'iba ulok ri 'av ikiq'q'ab,

Vil na," x ch'a ri baq.

"Ve,"

Xch'a q'u q'apoh.

$X$ u lik'iba akan ok

Uv-ikiq'q'ab ch u vach baq.

Kate q'ut chi pitz ka ban u chub baq

Ta x petik tak'al q'ut p u q'ab q'apoh.

Ta $x$ rilq'ut u p u q'ab;

Hu zuq $x$ u nik'oh

Ma q'u ha bi, u chub baq p u q'ab.

O resultado desse diálogo entre os dois personagens será a imediata gravidez de X Kiq (Moça de Sangue), que terá de fugir de Xibalba, a fim de alcançar a superfície da Terra, onde dará à luz os Gêmeos, os grandes heróis do poema maia. Pode-se dizer que, nesse clássico da literatura indígena, os heróis épicos são filhos de uma cabeça cortada. Percebe-se claramente a importância desse tema mítico para toda a literatura ameríndia e, por extensão, para a literatura latino-americana moderna, que bebeu e ainda bebe nessa fonte, a partir de Miguel Ángel Asturias.

Os Gêmeos crescerão fortes e descerão a Xibalba, imbuídos do desejo de enterrar a cabeça falante do pai. Num dos pontos culminantes do Terceiro Canto, e talvez de toda a literatura ameríndia, os heróis épicos se acercam da cabeça do pai, a fim de ajudá-la a morrer, ou a aceitar a própria morte ${ }^{6}$ :

Pois realmente sua face desejava existir, 
E lhe perguntaram o nome de todas as coisas,

Sua boca,

Seu nariz,

A cavidade

Do olho.

No começo ele encontrou o seu nome.

Mas quase mais nada pôde falar.

Não pôde falar mais

O nome dos lábios de sua boca,

Assim ele não pôde realmente falar.

E assim então eles o reverenciaram

E reverenciaram o coração de seu pai.

Xa vi xere ' $u$ vach $x r$ ah uxik,

$X$ tz'onox q'ut chi re 'u bi r onohel,

U chi,

Utzam,

Ubaq',

Uvach,

$X$ u riq nabe ' $u$ bi,

Xa q'u zkakin chik $x$ ch'atah vi.

Xere ma vi $x$ u biih chik

U bi ri, u hunal puvil u chi,

Xere pu $x$ ch'atah chi vi.

Kehe q'ut ta $x$ ki nimah vi

Kanah ok u k'ux ki qahav.

O pai (cabeça cortada) aceita finalmente a morte, pois compreende que já não possui a linguagem e os nomes, isto é, tudo o que é preciso saber para louvar os deuses. Seus filhos poderão agora cumprir seu próprio destino. Quando a cabeça de Um Caçador é devolvida à cova, ou seja, quando é devidamente inumada, nasce, com suas implicações culturais e espirituais, o funeral maia..

Acredito que esses exemplos maias sirvam para ilustrar a importância da cabeça cortada no imaginário ameríndio, imaginário que, ouso afirmar, continua a influenciar a literatura que se faz hoje na América Latina, seja ela oral ou escrita. 


\section{BIBLIOGRAFIA}

BROTherston, G., MEDEIROS, S. (orgs.) Popol Vuh. São Paulo: Iluminuras, 2007

EDMONSON, M. The Book of Counsel: The Popol Vuh of the quiche maya of Guatemala. New Orleans: Tulane University Press, 1971.

SERRES, M. Gênese. Paris: Bernard Grasset, 1982.

\section{NOTAS}

I BROTHERSTON, MEDEIROS, 2007, p. 9.

2 BROTHERSTON, MEDEIROS, 2007, pp. 43 - 45.

3 BROTHERSTON, MEDEIROS, 2007, p. 17.

4 BROTHERSTON, MEDEIROS, 2007, p. 143.

5 BROTHERSTON, MEDEIROS, 2007, p. 147.

6 BROTHERSTON, MEDEIROS, 2007, p. 259. 